\title{
Expressões das experiências místicas: natureza e intensidade
}

\author{
Expressions of mystical experiences: nature and intensity
}

\author{
Soraya Cristina Dias Ferreira *
}

\begin{abstract}
Resumo
Esta comunicação faz parte de uma pesquisa doutoral que propõe analisar as expressões das experiências místicas revisitando o novo olhar que a Psicologia Analítica de Jung percorre ao amplificar o tema. Busca compreender a natureza e a intensidade dos fenômenos místicos que acontecem quando o humano se abre para experienciar os aspectos do numinoso em seu vir-a-ser, encontrando nas imagens primordiais - matrizes de comportamentos herdadas pelo humano experiências mais fundantes, com tendências a repetições e/ou similaridades. Discute a relevância do processo de individuação que encontra na dialética dos opostos uma amplificação da consciência capaz de levá-lo à inteireza. Essa natureza compreendida e essa intensidade atingida com a ajuda dos símbolos vivos possibilitam ao humano ser partícipe de uma privilegiada coniunction (união dos opostos) que o ajuda a atingir um centro mais profundo, como se observa na vida de vários místicos da cultura oriental e ocidental.
\end{abstract}

Palavras-chave: mística; experiência; intensidade; natureza; transcendência.

\begin{abstract}
This communication is part of a doctoral research which proposes to analyze the expressions of the mystical experiences revisiting the new sight that the Analytical Psychology of Jung goes through amplifying the theme. It seeks to understand the nature and intensity of the mystical phenomena that take place when the human opens up to experience the aspects of the numinous in his becoming, finding in the primordial images - matrices of behaviors inherited by the humanmore founding experiences, with tendencies to repetitions and / or similarities. It discusses the relevance of the process of individuation that finds in the dialectic of opposites an amplification of consciousness capable of bringing it to wholeness. This understood nature and this intensity achieved with the help of living symbols enables the human to participate in a privileged coniunction (union of opposites) that helps him to reach a deeper center, as can be noticed in the lives of several mystics of Eastern and Western culture.
\end{abstract}

Keywords: mystique; experience; intensity; nature; transcendence.

Comunicação submetida em 01 de abril de 2019 e aprovada em 30 de agosto de 2019.

*Doutoranda em Ciências da Religião pela PUC Minas com pesquisa financiada pela CAPES e PUC Minas. Mestra em Ciências da Religião e Especialista em Psicologia Analítica Junguiana pela PUC Minas. Psicóloga Clínica e professora. Esta comunicação foi apresentada em mesa redonda no VIII Encontro Integrado da Psicologia da PUC Minas. País de origem: Brasil. E-mail: sorayacdferreira@gmail.

Horizonte, Belo Horizonte, v. 17, n. 53, p. 1283-1293, maio/ago. 2019 - ISSN 2175-5841 


\section{Introdução}

Toda construção de um determinado saber tem como problema fundamental, e polêmico, o conhecimento verdadeiro e seguro. Será ele possível? Como decidir, num caso determinado, se essa ou aquela aquisição do conhecimento é efetiva? Em se tratando de o humano ser objeto central das ciências humanas, o ato de conhecer é, então, ligado a uma complexidade de conceitos pré-estabelecidos como "verdades" o que traz inúmeras dificuldades para compreensão da dinâmica psíquica em sua rede relacional, ou seja, na interação de sua estrutura trial (corpo, alma/mente e espírito) em ação no mundo externo/objetivo e interno/subjetivo. Como nos cita Bachelard (1974):

É no próprio ato de conhecer, intimamente, que aparecem, por uma espécie de imperiosidade funcional, as lentidões e as dificuldades. Aí é que mostraremos causas de estagnação e até de regressão; aí é que discerniremos causas de inércia que chamaremos de obstáculos epistemológicos. O conhecimento do real é uma luz que projeta sempre alguma parte de sombras. Ele jamais é imediato e pleno. As revelações do real são sempre recorrentes. O real jamais é "o que se poderia crer", mas é sempre o que se deveria ter pensado. [...] Retornando a um passado de erros, encontramos a verdade num autêntico arrependimento intelectual. De fato, conhecemos contra um conhecimento anterior, destruindo conhecimentos mal feitos, superando-se o que, no próprio espírito, cria obstáculo à espiritualização. (BACHELARD, 1974, p.147).

Portanto, se o conhecimento é modificado através dos tempos, como demonstra a própria história das inovações científicas, determinadas investigações acabam exigindo um aporte analítico crítico que revisite alguns dos saberes e métodos já constituídos e de certa forma até rejeitados pelo poder do empirismo. Isso se constitui numa tentativa de, primeiramente, contextualizar o tema pesquisado para, posteriormente, passar por uma amplificação que não perca de vista o fato de que as pesquisas contemporâneas da Mística - em contato com a problemática do conhecimento já formulado e com realidades encontradas no vivido de certos desenvolvimentos espirituais - ainda carecem de avanços, principalmente na área que se dedica aos estudos da Psiquiatria e Psicologia quando as expressões do fenômeno religioso no dinamismo psíquico torna-se material de análise. 
Tendo em vista esse entendimento prévio e panorâmico, a preocupação central que permeia nosso objetivo de investigação, ao escolher abordar o fenômeno da Mística como algo que deva ser compreendido na sua essência e, não apenas, pelos rótulos clássicos encontrados nos estudos sobre o dinamismo psíquico religioso, é uma tentativa de sair das visões parciais do que em nosso mundo contemporâneo está denominando como equilíbrio Mental no contexto que aqui se insere. E, ainda, buscar na complexidade dos fenômenos religiosos, espirituais e místicos, que erroneamente encontram-se em analogias aos processos neuróticos e/ou psicóticos, qual a sua real natureza e intensidade.

\section{Expressões do relativo ao Uno e ao Todo}

A partir do conhecimento de certo percurso histórico nos primórdios da Psicologia como ciência independente, constata-se a relevância de se ir ao encontro de concepções humanas que conseguiram conciliar teoria e práxis para transformar o processo apreendido em linguagem psicológica. Evidenciamos, não obstante ser uma obra extensa e densa, a necessidade de adotar como referencial teórico, o pensamento de Jung (1875-1961) e Edith Stein (1891-1942). Já que o autores tentam captar nas apreensões de mundo, concepções que não decapitarão o humano cientista do humano vivente.

Nesta comunicação optamos por dar enfoque ao pensamento de Jung. Sua autoexperimentação apresentada no Liber Novus (2010) torna seus escritos fecundos cálices sobre a "inefabilidade" do Sagrado, que paradoxalmente, deixa rastros possíveis de serem capturados por um intelecto que vai além do discursivo e se aventura em demostrar existir na alma uma busca que pode culminar na Inteireza do ser humano, em uma frutífera coniunctio (união dos opostos) que o religa as grandezas do Si-mesmo/Self. ${ }^{1}$

\footnotetext{
${ }^{1}$ Postulado psicológico que expressa a totalidade psíquica do ser humano, entendendo-a como um dinamismo onde forças conscientes, inconscientes e do inconsciente coletivo - representações arquetípicas - atuam na dinâmica psíquica.
} 
O aprofundamento dessas análises foram suscitadas por algumas inquietações primeiras e estas advêm do contato com estudos da Antropologia e da Psicologia Profunda: Quem é o humano? Quais concepções que de forma complementar nos apresentam o seu lugar no cosmos? Existe nele um desenvolvimento espiritual inato? Como sua formação humana espiritual se estrutura ao nível de organização psíquica? Como em seu processo de individuação ele se relaciona com a Função Transcendente ${ }^{2}$ para chegar a uma possível inteireza, a um certo reconhecimento de um certo Centro mais profundo?

Como ponto de partida, para as questões levantadas, Jung afirma que "Tudo o que é humano é relativo, porque repousa numa oposição interior de contrários, constituindo um fenômeno energético”. (JUNG, 2011a, p.87). Encontramos, então, em sua concepção humana novos direcionamentos sobre a estrutura humana em essência, formação e interações. Considerado um microcosmo pertencente a um macrocosmo que na sua grandeza, oculta partes, seu processo de individuação 3 encontra na dialética dos opostos a possibilidade de novas organizações psíquicas. Estas podem favorecer o alcance de sua inteireza, pois o estado de perfeição não é pauta para um ser que se encontra desde sua concepção em atos transformacionais psíquicos, biológicos, culturais, sociais e espirituais o que lhe exigem certo contato com sua natureza arcaica e singular, na plena consciência de que,

O indivíduo pode empenhar-se na busca pela perfeição ("Sede perfeitos [teleioi] como vosso Pai celeste é perfeito", Mt 5,48), mas é obrigado a suportar, por assim dizer, o oposto do que intenciona, em benefício da sua inteireza ("Por conseguinte, dentro de mim encontro esta Lei: quando quero fazer o bem, é o mal que se acha dentro de mim”, Rm 7,21). (JUNG, 2011b, p.87).

\footnotetext{
${ }^{2}$ Função psíquica (não metafísica) que auxilia o ser humano em seu processo de autoconhecimento/autodomínio, pois equaliza os conteúdos conscientes e inconscientes. Possibilitando a transposição de atitudes, sem que a perda de seus conteúdos aconteça.

${ }^{3}$ A individuação é para psicologia de Jung um processo pelo qual o humano torna-se si mesmo ao abrir-se para os caminhos do autoconhecimento e este pode levá-lo a experienciar certa totalidade psíquica.
} 
A luta imposta pela dinâmica do autoconhecimento passa por caminhos que ressignificados pela própria "substância” contida em si mesmo, no nível singular, encontra na pluralidade relacional a força para atravessar os lados sombrios de sua natureza através do ato criativo também inerente a sua complexidade psíquica. Nela, sua natureza corpórea unifica-se com sua alma (anima) e com seu pleroma/espírito.

Assim, ao analisar os caminhos que alguns humanos considerados místicos percorreram, encontramos certa repetição das imagens arquetípicas em que, apesar dos diferentes aspectos interpsíquicos e intrapsíquicos, o humano conscientemente aberto ao vir-a-ser espiritual consegue chegar a certa coniunction ao estabelecer contato com unidades que ultrapassa o seu si mesmo, ao mesmo tempo que lhe revela a essência de sua natureza. Essa intensidade experienciada no vir-a-ser de humanos que busca sentir os aspectos do numinoso 4 como meta de vida, exige maiores aprofundamentos. Nisso consiste a pretensão da pesquisa supracitada.

Porém, cabe aqui reafirmar que independente dos "sintomas" encontrados ou não na psique como efeito causal dos fenômenos religiosos ou não, torna-se importante compreendê-los como caminhos que promovem processos transformacionais e estes envolvem também a vivacidade acausal dos símbolos vivos a serem constantemente ressignificados, pois,

Se nossa consciência não tentar entender os símbolos trazidos pelo nosso mundo inconsciente - que traz conteúdos subjetivos, coletivos e autônomos - e preferir negar esta parte a ser analisada, os símbolos vivos podem se tornar símbolos mortos. Nesta experiência, o não se confrontar com a persona, pode impedir o sujeito de avançar em águas mais profundas do seu si mesmo. Isto não impede o fluir do processo de individuação, mas a função transcendente, que depende de uma atitude da consciência para uma nova organização do caos psíquico, fica oculta, clamando para emergir, para quebrar este medo das manifestações internas, pois a individuação pressupõe passagens e integrações que ajudam na autorealização, e está se compõe através das experiências negativas e positivas, nos símbolos que evocam algo além do simples manifesto. (FERREIRA, 2017, p.119)

\footnotetext{
${ }^{4}$ Termo usado pelo teólogo protestante Rudolf Otto (1869-1937) e retomado por Jung para evidenciar a característica principal do arquétipo, sua força autônoma na dinâmica psíquica.
} 
Como ressalta Jung, em sua construção científica, foi necessário deixar de lado a "orientação personalística" da Psicologia para compreender a natureza conservadora, amedrontadora e libertadora da dinâmica psíquica. Conceitos como sombra, persona, animus-anima, dentre outros 5 e a compreensão dos Tipos Psicológicos (introvertido e extrovertido) predominantes tornam-se importantes amplificações sobre os dinamismos psíquicos cuja essência manifesta-se devido a diferentes tonalidades afetivas que por serem autônomas perturbam a energia psíquica, até que novas compensações possam acontecer.

Estes fatores da energia psíquica, demonstram ser tarefa do autoconhecimento buscar equilibrar a intensidade das funções: pensamento, sentimento, sensação e intuição, qual seja a experiência relacional que o humano elege. Observa-se que nos místicos a consciência desse enfrentamento é intensificada em sua práxis religiosa, espiritual e/ou existencial. Qual, então, será o método mais adequado para lidar com essa abrangente e dinâmica energia psíquica ao nível científico? Jung (2011a) destaca:

\begin{abstract}
A "análise", na medida em que se restringe à decomposição, deve ser necessariamente por uma síntese. [...] tive de me convencer da existência de um material psíquico praticamente desprovido de significado quando simplesmente decomposto, mas que encerra uma plenitude de sentido ao ser confirmado e ampliado por todos os meios conscientes (é a chamada amplificação). Os valores das imagens ou símbolos coletivo só aparecem quando submetidos a um tratamento sintético. Como a análise decompõe o material simbólico da fantasia em seus componentes, o processo sintético integra-o numa expressão conjunta e coerente. Este processo não é simples. (JUNG, 2011a, p.93).
\end{abstract}

Percebe-se, logo, a necessidade de um estudo cujas matizes determinam caminhos analíticos que culminam em contribuições sobre a existência de um certo Centro mais Profundo na alma humana. Centro coabitado pelo mistério, mas que nos revela através do autoconhecimento e amplificações dos símbolos vivos,

\footnotetext{
${ }^{5} \mathrm{Na}$ construção de sua Psicologia Complexa, Jung descreve conceitos importantes para integração de certa totalidade psíquica. A sombra representa os lados sombrios, as projeções e porções normalmente reprimidas da personalidade; a persona é uma analogia às máscaras, que representa uma personalidade artificial por distanciar o humano de si mesmo enquanto vive determinados papeis sociais; Animus-anima: importante arquétipo da vida psíquica por representar um sistema herdado da feminilidade e masculinidade que necessita equilibrar-se no ser singular.
} 
possíveis mediações entre o humano e um Deus coparticipativo da desenvoltura da alma por nela estar, de certa forma, contido. Porém sua forma indireta de desvelamento deixa para a Psicologia Complexa - também conhecida como Psicologia Analítica - uma inquietação epistemológica à compreensão das ideias psicológicas retroalimentadas e o seu real campo de atuação no humano espiritual, já que "O conceito Deus é simplesmente uma função psicológica necessária, de natureza irracional, que absolutamente nada tem a ver com a questão da existência de Deus”. (JUNG, 2011a, p.82-83).

Estas Reflexões nos ajudarão a compreender se a experiência mística é gerada por outras fontes que envolvem abertura da energia psíquica a fenômenos inatos o que transcende o estudo das crenças religiosas e arreligiosas para adentrar no espaço da natureza e intensidade psíquica. Mesmo compreendendo a importância dada pela Teologia que enfoca a gratuidade, da filosofia Kantiana com sua análise sobre dos conteúdos a priori, buscar-se-á mediante a essas inquietações teóricas transdisciplinares e às vezes até mesmo divergentes, alcançar uma reflexão psicológica, pela qual a essência dos fenômenos manifestos provoque uma enantiodromia ${ }^{6}$ construtiva.

Para tanto, encontramos na Psicologia Complexa/Analítica a afirmativa de que são os símbolos vivos, como infinitos mediadores de experiências religiosas e arreligiosas, o fecundo caminho de averiguação, pois a repetição e/ou similaridades de imagens arquetípicas encontrada facilita ao humano amplificar o que lhe transcende. Isso torna o seu caminho existencial expressão máxima do reconhecimento de que "Profundeza e superfície devem misturar-se para que surja nova vida, mas a nova vida não nasce fora de nós, e sim dentro de nós". (JUNG, 2010, p.239). Como possibilidade do uno alcançar o todo.

\footnotetext{
${ }^{6}$ Termo reformulado por Jung para representar a existência de contrários no fenômeno energético.
} 


\section{Expressões do reverso à organização psíquica}

Seja qual for o nível de crença (científica, ética e/ou religiosa) esse desvelar o obscuro provoca uma nova organização psíquica e essa, quando prioriza o desenvolvimento espiritual, o sentido absoluto, deixa rastros do experienciar em si aspectos do numinoso em estado humano de inteireza. Portanto, essa interação que busca promover o crescimento espiritual e culmina em certa união mística não deve ser confundida com estados alterados de consciência e/ou fenômenos psicopatológicos, já que mundo externo, vida íntima e condições psíquicas não são vivências estanques. São, ao contrário, determinantes para que o encontro místico deixe explicito a valoração das relações efetivadas pelo respeito aos processos que ligam objetividade e subjetividade ao desenvolvimento espiritual. Como nos alerta Merleau-Ponty (1999):

O mundo é inseparável do sujeito, mas de um sujeito que não é senão projeto do mundo, e o sujeito é inseparável do mundo, mas de um mundo que ele mesmo projeta. O sujeito é ser no mundo, e o mundo permanece "subjetivo", já que sua textura e suas articulações são desenhadas pelo movimento de transcendência do sujeito. Portanto, com o mundo enquanto berço das significações, sentido de todos os sentidos e solo de todos os pensamentos, nós descobrimos o meio de ultrapassar a alternativa entre realismo e idealismo, acaso e razão absoluta, não sentindo e sentindo. (MERLEAU-PONTY,1999, p. 576).

Para isso, a objetividade não pode excluir o que sempre necessitará de novas hermenêuticas para compreensão do humano como objeto de estudo, principalmente em relação às desenvolturas que favorecem o alcance de certa totalidade psíquica. Ou seja, energia relacional, perceptível nas vivências oportunizadas pela junção do movimento do mundo externo e interno já que: "A alma se encontra em seu mundo e consigo produz um mundo. No mundo ela se expressa para outros. Cria obras no mundo". (JASPERS, 2000, p.25). Essas obras não advêm de uma construção já compactada em estruturas de pensamento dual, mas da desenvoltura múltipla da existência humana onde a energia psíquica se insere para desvelar novas profundidades do eu, no equilíbrio compensatório entre consciência, inconsciente e inconsciente coletivo, como enfatiza Jung na envergadura de sua obra. 
Portanto, por mais que o eu exterior encontre apoio no solo da objetividade, a consciência - centro de orientação - é atravessada pelo não-eu a ela correspondente, talvez porque certas profundidades do eu, ao reconhecerem a unidade dos opostos abrem-se para a elevação da alma. No pensamento junguiano, as imagens arquetípicas pertencem a esses dinamismos, pois elas tendem às repetições e/ou similaridades que estão contidas na experiência vital herdada, demonstrada na história de místicos ocidentais e orientais, pois "O arquétipo é uma ideia viva, que sempre, de novo, dá impulso a novas interpretações, nas quais se desdobra”. (JUNG, 2011c, p.346). Sua dinâmica acontece nos humanos em desenvolvimento espiritual ou não; mas, àqueles cuja abertura procura com entrega o efeito do numinoso, por ele pode ser inebriado ao nível consciente, inconsciente e arquetípico, como uma "devotion" ao mais profundo de si mesmo, que encontra em sua natureza a intensidade do instante supremo.

O Si-mesmo (Selbst), estado experienciado na mais alta inteireza que o humano possa alcançar, conduz o ser a níveis superiores de consciência. Encadeamentos não causais, pertencentes à dinamicidade do universo dos símbolos vivos que engloba vivências atemporais por ter a capacidade de levar o humano a tocar - pela experiência imediata - o desconhecido, ou seja, certa totalidade psíquica matizada pelo alcance de um certo centro mais profundo, e este modifica-o porque é um ato relacional que culmina na amplificação de sua essência singular e plural que vai além de qualquer pertencimento institucional religioso.

\section{Considerações finais}

Constata-se, mesmo diante das diferentes expressões encontradas no humano que busca sentir o numinoso e/ou compreender Deus como experiência mediada pela fenomenologia de sua dinâmica psíquica, a necessidade do reconhecimento de que a situação psíquico-emocional, em cujo cerne há projeções, estruturas da personalidade, até mesmo possíveis de ser enquadradas no saber psiquiátrico e fenômenos religiosos cada vez mais diversificados, são apenas partes de um grande processo transformacional. A alma, ao abrir-se para o 
autoconhecimento que busca os aspectos até então a ele obscuros, acessa níveis de profundidades do eu que a ciência ainda investiga, por serem os caminhos mais contundentes de verificação.

Nesse sentido, o cerne investigativo das expressões místicas do ponto de vista da Psicologia Complexa/Analítica, demostram que o humano pode tornar-se inteiro quando natureza e intensidade encontram-se em profundidades do eu que foram tocadas pelos aspectos numinosos. Só assim, o ponto fundante da energia psíquica espiritual se efetivará no reconhecimento de uma natureza transformacional que, através das imagens arquetípicas universais pertencentes a psique coletiva, matizada pela irreptível subjetividade, religa-o ao Absoluto. Tal pensamento acaba oferecendo um sentido profundo para o ethos do humano contemporâneo, que cada vez mais acelerado e plural, até mesmo ao nível de religiosidade, deve abrir-se para compreender sua natureza que, em intensidade, pode alcançar a "abrangência completa da psique", ou seja, a máxima intensidade, o Self/totalidade psíquica.

\section{REFERÊNCIAS}

BACHELARD, Gaston. Epistemologia. 2. ed. Rio de Janeiro: Zahar Editores, 1974.

FERREIRA, Soraya. Freud \& Jung: do complexo de Édipo à alma naturalmente religiosa. Porto Alegre, RS: Editora Fi, 2017. Disponível em: http://editorafi.org/141soraya. Acesso em: 20 maio 2019.

JASPERS, Karl. Psicopatologia geral: psicologia compreensiva, explicativa e fenomenologia. 8. ed. São Paulo: Atheneu, 2000. 2 v.

JUNG, C. G. Aion: estudos sobre o simbolismo do si-mesmo. 8. ed. Petrópolis, RJ: Vozes, 2011b. (Obras completas, v. 9/2).

JUNG, C. G. O livro vermelho: liber novus. Petrópolis: Vozes, 2010.

JUNG, C. G. Psicologia do inconsciente. 19. ed. Petrópolis, RJ: Vozes, 2011a. (Obras completas, v. 7/2). 
JUNG, C. G. Mysterium Coniunctionis: pesquisas sobre a separação e a composição dos opostos psíquicos na alquimia. 2. ed. Petrópolis: Vozes, 2011c. (Obras completas, v. 14/2).

MERLEAU-PONTY, Maurice. Fenomenologia da percepção. 2. ed. São Paulo: Martins Fontes, 1999. 